\title{
A importância das Tecnologias de Comunicação e Informação (TIC) como ferramenta pedagógica na educação infantil e nas séries ini- ciais do Ensino Fundamental
}

\author{
The importance of Communication and Information Technologies (ICT) as a pedagogical tool in ear- \\ ly childhood education and warly years of elementary education
} Jean André de Souza ${ }^{\dagger *}$, Eliene Maciel Cirilo ${ }^{\dagger}$, Nathalia Diogo da Silva ${ }^{\dagger}$, Maria Fernanda Caravana de
Castro Moraes Ricci", Marinéa da Silva Figueira Rodrigues ${ }^{\ddagger}$

Como citar esse artigo. Souza, J. A.; Cirilo, E. M.; Silva, N. D.; Ricci, M. F. C. M. \& Rodrigues, M. F. A importância das Tecnologias de Comunicação e Informação (TIC) como ferramenta pedagógicanaeducaçãoinfantilenasséries iniciais do Ensino Fundamental. Revista Mosaico. 2017 Jul./Dez.; 08 (2): 48+50.

\begin{abstract}
Resumo
Esta pesquisa tem como objetivo investigar a importância das Tecnologias de Comunicação e Informação (TIC) como ferramenta pedagógica no processo ensino-aprendizagem na Educação Infantil e nas Séries Iniciais do Ensino Fundamental. Para tanto, realizou-se uma pesquisa de cunho bibliográfico, baseada em renomados autores no assunto, a saber: Almeida (2004), Alonso (2012), Barros (2005) Dowbor (2001), Thomé (2015), dentre outros. As TIC auxiliam a prática docente, possibilitando o professor trabalhar com diversos tipos de ferramentas e aplicativos que tornarão suas aulas mais interessantes e motivadoras e a aprendizagem do aluno mais produtiva e interativa.

Palavras-Chave: Educação; Ensino e Aprendizagem; Tecnologia da Informação e Comunicação.
\end{abstract}

\begin{abstract}
This research aims to investigate the importance of Communication and Information Technologies (ICT) as a pedagogical tool in the process of teaching learning in Early Childhood Education and Early Years of Primary Education. To that end, a bibliographic research was carried out, based on renowned authors in the subject, namely: Almeida (2004), Alonso (2012), Barros (2005) Dowbor (2001), Thomé (2015) among others. ICT help teachers, enabling the teacher to work with different types of tools and applications that will make their classes more interesting and motivating and student learning more productive and interactive.

Keywords: Education; Teaching and learning; Technology of Information and Communication.
\end{abstract}

\section{Introdução}

O século XXI é considerado o século da informação, da sociedade do conhecimento. As Tecnologias de Informação e Comunicação (TIC) desempenham papel crucial nas transformações que ocorrem em nosso planeta e, consequentemente, na área de educação, uma vez que elas, segundo Dowbor (2001, p.11) "não é uma área em si, mas um processo permanente de construção de pontes entre o mundo da escola e o universo que nos cerca". Por isso, se faz tão importante a utilização dessas ferramentas nos espaços escolares.

Os materiais educativos digitais e as práticas pedagógicas inovadoras surgem como meios para potencializar o processo de ensino aprendizagem e o desenvolvimento dos aspectos cognitivos e sociais do educando, permitindo um trabalho autônomo, de recolha, de seleção e verificação de informações e o conhecimento de outras culturas através de uma maior abertura ao mundo. Os recursos audiovisuais também provocam no educando um encantamento, envolvendo-o por meio da variação de cores, movimento e imagens, faz com que ele queira aprender e saber mais sobre a informação que está sendo visualizada.

Partindo dessa premissa, esta pesquisa tem por objetivo mostrar a importância das TIC como ferramenta pedagógica de suma relevância no trabalho do professor com crianças da Educação Infantil e das Séries Iniciais do Ensino Fundamental. A metodologia utilizada será de revisão de literatura da temática, baseada em livros e artigos científicos de renomados autores no assunto.

Afiliação dos autores: † Discente - Graduação da Universidade Severino Sombra - USS, Vassouras-RJ, Brasil.

\$ Docente da Universidade Severino Sombra - USS, Vassouras-RJ, Brasil.

* jean.souza18@yahoo.com.br 


\section{TIC e seus benefícios para a Educação}

A integração das TIC na educação é algo novo e crescente. Muito se tem questionado a respeito dessa nova ferramenta pedagógica de interação. Com o crescimento da oferta de conexão (wi-fi, gprs, 3G, Mesh, etc.) se torna cada vez mais necessário que profissionais de educação usem mais intensamente os recursos da internet.

Para Almeida (2004, p.8) "a inserção das TIC na educação oportuniza romper com as paredes da sala de aula e da escola, integrando-a à comunidade que a cerca, à sociedade da informação e a outros espaços produtores de conhecimento".

Para Freire (1987), os homens aprendem em comunidade. Se as pessoas (de diferentes contextos culturais, visões de mundo e níveis cognitivos) estiverem conectadas, maiores as possibilidades de situações de aprendizagem.

As TIC potencializam estas interações, criando novos espaços de aprendizagens, uma vez que as crianças, desde cedo, estão cada vez mais ligadas ao uso de aparelhos eletrônicos (computadores, tablets, smartphones, iPads e iPods) no seu dia-a-dia, podendose afirmar, na visão de Papert (1994), que entre crianças e computadores existe um caso de amor, e a escola não pode se isentar dessas inovações.

Através do uso das TIC podemos aproximar o conteúdo de estudo com a vida cotidiana da criança, despertando nela o desejo de estabelecer comunicações, produzir e publicar histórias, contar acontecimentos do seu cotidiano, trocar experiências, como também desenvolver o prazer pela leitura e escrita.

Tomé (2015) salienta que as tecnologias são imprescindíveis no aprendizado infantil, pois desenvolvem diferenciadas e ricas estratégias, fazendo com que os educandos aprendam de forma lúdica, dinâmica e prazerosa, respeitando suas limitações e individualidades.

A importância de inserir novas tecnologias em ambientes escolares é para gerar coisas novas e pedagogicamente importantes que não se pode acontecer de outras formas. A escola passa a ser um ambiente mais interessante que aprontaria o aluno para o seu futuro, tornando-o um utilizador independente da informação, capaz de usar vários tipos de fontes de informação e meios de comunicação.

\section{Papel do professor na utilização das TIC}

Para Alonso (2012), a utilização das TIC na sala de aula só será útil quando o professor tiver condições de interpretar, refletir e dominar criticamente a tecnologia. Convém salientar que não se trata de utilizar a qualquer custo as tecnologias, mas sim de acompanhar conscientemente uma mudança de civilização que está questionando profundamente as formas institucionais dos sistemas educativos tradicionais e, notadamente, os papéis de professor e aluno.

A integração das TIC no currículo implica investimento em dois domínios: na atitude dos professores e numa adequada capacitação para o seu uso (SILVA; MIRANDA, 2005; PERALTA; COSTA, 2007).

A capacitação dos professores é o ponto crucial, pois os alunos estão quase sempre prontos para a utilização das tecnologias, enquanto a maioria dos professores não. Já Barros (2005) nos salienta que as aulas dadas tradicionalmente estão gerando desinteresse e atualização de informações pelas tecnologias por parte dos alunos, o que está abalando o conhecimento "incontestável' dos professores, sendo assim, o "amplo" desafio consiste em inteirar os professores com a cultura tecnológica para o processo de ensino-aprendizagem".

Rocha (2001) afirma que é necessário ter cautela ao usar a tecnologia, o professor precisa ter a percepção de que quem dita as regras é a educação, sendo a tecnologia uma ferramenta a mais do fazer pedagógico. Ela não pode ser considerada o centro da ação.

Os professores poderão desenvolver atividades envolventes e significativas que cativem os seus educandos a trabalharem de forma mais enriquecedora nesse mundo virtual, podendo ser utilizados nas aulas os jogos educativos em variados sites, vídeos no YouTube, letramento e alfabetização com a utilização de atividades que envolvam letras, nomes e figuras, dentre outras. É preciso desenvolver com todas as tecnologias: as telemáticas, as audiovisuais, as textuais, as orais, musicais, lúdicas e corporais.

Finalizando, o professor não pode deixar de estabelecer objetivos e critérios ao utilizar este recurso, pois a utilização inadvertida não enriquece as aulas, tornando-se um tempo inutilizado para a construção e a troca de conhecimentos. Ensinar com as novas mídias será uma revolução, se mudarmos simultaneamente os paradigmas convencionais do ensino, que mantêm distantes professores e alunos. Uma vez que Vygotsky (1984) afirma que é na interação entre aqueles que sabem mais com aqueles que ainda não conseguem fazer sozinhos que o pensamento se desenvolve.

\section{Referências}

ALMEIDA, Maria Elizabeth Bianconcini. Tecnologia de Informação e Comunicação na Escola: novos horizontes na produção escrita.(2004). Disponível em: <www.iar.unicamp.br/disciplinas/mm.../doc/TI\%20e\%20 CM\%20na\%20escola.doc>. Acesso em: 22 de jul. 2017.

ALONSO, Myrtes, et al. Formação de gestores para utilização de tecnologias de informação e comunicação. São Paulo: Takano, 2002. ANDRADE, Pedro Ferreira de. Aprender por projetos, formar educadores. In: VALENTE, Jose Armando (org.). Formação de educadores para o uso da informática na escola. Campinas-SP: Unicamp/Nied, 2003. Disponível em: http:// 
www.nied.unicamp.br/?q=content/formação-de-educadores-para-o-usodainformática-na-escola; (2) http://www.nied.unicamp.br/oea/pub/livro4/. Acesso em: setembro 2017.

BARROS, D.M.V. Tecnologias da inteligência: gestão da competência pedagógica virtual. Tese (Doutorado em Educação Escolar) - Universidade Estadual Paulista, Faculdade de Ciências e Letras, Campus de Araraquara, 2005.

DOWBOR, Ladislau. Tecnologias do Conhecimento: os desafios da educação. Petrópolis/RJ: Editora Vozes Ltda., 2001.

FREIRE, P. Pedagogia do oprimido. 17 ed., Rio de Janeiro: Paz e Terra, 1987.

PAPERT, Seymourt. A Máquina das Crianças:repensando a escola na era da informática. Trad. Sandra Costa. Porto Alegre, Artes Médicas, 1994.

PERALTA, H. COSTA, F. Competência e confiança dos professores no uso das TIC. Síntese de um estudo internacional.Sisífo/ Revista de Ciências da Educação, no 3 , maio/ago 07, p.77-86

SILVA, F.; MIRANDA, G. Formação Inicial de Professores e Tecnologias. In: P. Dias \& Freitas V. Atas da IV Conferência Internacional de Challenges. Braga: CC Nónio Sec - XXI, UM, p. 593- 606, 2005.

SILVA, P. A. R. S; PEREIRA, C. C. Formação Contínua de Professores: integração das TIC(2011) Disponível em: <file://C:/Users/jeans_000/ Desktop/139_151.pdf>. Acesso em: 30 out. 2017.

ROCHA, C. A. A Interferência da Cultura nos Softwares Educacionais: o desafio de alertar sobre as práticas discriminatórias. Curitiba, 2001. 165 f. Dissertação (Mestrado em Tecnologia) Programa de Pós-Graduação em Tecnologia, Centro Federal de Educação Tecnológica do Paraná.

TOMÉ, Thalita. A importância da Tecnologia no aprendizado infantil. DINO - Divulgador de notícias. 2013. Disponível em: $<$ htps://www.dino. com.br/releases/aimportancia-da-tecnologia-no-aprendizado-infantildino8902670131/pdf>. Acesso em: 20 de jul. 2017.

VYGOTSKY, Lev S. A formação social da mente. São Paulo: Martins Fontes, 1984. 